\title{
The Unbureaucratic Personality
}

\author{
Leisha DeHart-Davis \\ Assistant Professor \\ University of Kansas \\ 1541 Lilac Lane \#318 \\ Lawrence, KS 66045-3177 \\ Phone: (785) 864-3527 \\ Fax: (785) 864-5208 \\ lddavis@ku.edu
}




\section{The Unbureaucratic Personality}

After sixty years of scholarship on the rule-bound bureaucratic personality, this article turns attention to the unbureaucratic personality. Identified by a willingness to bend rules, the unbureaucratic personality is thought to be influenced by individual and workplace attributes, each which shed light on the nature of rule-bending. Individual attributes investigated include nonconformity, risk propensity, and public service commitment, all expected to stimulate the unbureaucratic personality. Workplace attributes include formalization and centralization, which are expected to suppress the unbureaucratic personality, and red tape, which is expected to trigger it. These hypotheses are tested using mail survey data collected from employees of four cities in a Midwestern state. The results of ordered probit modeling of the data suggest that nonconformity and risk taking increase the unbureaucratic personality, as do red tape and centralized workplaces. By contrast, the unbureaucratic personality appears to be lowered by public service commitment and workplace formalization. The implications of these results for the normative aspects of rule-bending are discussed. 


\section{Bio Statement and Disclosure}

Leisha DeHart-Davis is an assistant professor of public administration at the University of Kansas. Her research interests include the social psychological effects of organization structure and reforms on public employees and gender dimensions of the public sector workplace.

Data used in this paper were collected and analyzed with the support of a fellowship from the American Association of University Women; a new faculty grant from the University of Kansas; and research assistant support from the Institute for Policy and Social Research at University of Kansas. This support does not imply endorsement of the paper's analyses or opinions. The dataset is available upon request from the author. 


\section{The Unbureaucratic Personality}

The bureaucratic personality has been a topic of scholarly inquiry for over sixty years. This unfortunate figure has been characterized as overconforming (Merton 1940), insecure (Thompson 1977), and timid (Downs 1994), resulting in an unwillingness to depart even slightly from organizational rules. The persistence of this imagery is ironic given empirical evidence suggesting that $\mathrm{s}(\mathrm{he})$ does not exist in significant numbers in public or private organizations (Bozeman and Rainey 1998; Foster and Jones 1978; Allinson 1984, 1986; Stone and Feldman 1976; Foster 1990). Thus, the bureaucratic personality can be considered something of public administration's Sasquatch: a scary fleeting image to which our collective scholarly imaginations remain captive.

This article turns attention to an equally intriguing and arguably more favorable figure in public sector settings: the unbureaucratic personality. The unbureaucratic personality is a timely topic given the worldwide push for the public sector to “reinvent” itself by decentralizing decision-making and increasing worker discretion (Frederickson and Smith 2004, 207). Voices within the reinventing government literature call for a new type of government worker, one who is creative, entrepreneurial, and flexible (Osborne and Gaebler 1992, Cohen and Eimicke 1995). These latter descriptors from the popular literature imply that competent public servants will bend rules in the name of "customer service” and exercise significant discretion to achieve governmental results. Furthermore, massive rule bending is part and parcel of images of the trailblazing entrepreneurial public manager (Diver 1982). For these reasons, this paper focuses on conceptualizing the unbureaucratic public servant, one characterized by a tendency to bend organizational rules. 
Before engaging in this conceptualization, it should be clarified that the bureaucratic and unbureaucratic personalities are not flip sides of the same ideational coin. While the bureaucratic personality concept has evolved over time to represent an alienated individual that uses undue organizational rule abidance to overcome a sense of powerlessness (Bozeman and Rainey 1998), the unbureaucratic personality is a priori unattached to any particular dispositional trait. Given that this article seeks to craft an inductive portrait, the unbureaucratic personality is not conceptualized as antagonist to the bureaucratic personality.

It is also important to note that rule bending - like rule following -- can be organizationally pathological (Cohen 1965, Bensman and Rosenberg 1963) or beneficial (Merton 1940, Goodsell 2004). While definitive normative judgments are beyond the scope of this article, the intent here is to delve into the nature of the unbureaucratic personality by exploring its dispositional and organizational precursors. The dispositional factors considered by this study include nonconformity, risk-taking propensity, and public service commitment, all which are expected to increase the unbureaucratic personality. Organizational factors considered include centralization and formalization, which are expected to suppress the unbureaucratic personality, and red tape, which is expected to stimulate the unbureaucratic personality. The extent to which organization structure influences the unbureaucratic personality will suggest the reactionary nature and possible manipulability of rule-bending behavior, while the influence of individual disposition on the unbureaucratic personality will indicate its inherent nature (in addition to its potential uncontrollability).

A study of the employees of four cities in a Midwestern U.S. state provides the data for examining the unbureaucratic personality. In-person interviews with ninety employees in a range of hierarchical positions yielded qualitative background information, with a mail survey of all 
city employees generating the study's qualitative data. Response rates for the survey averaged 49 percent $(\mathrm{n}=645)$. Mail survey data are statistically analyzed to test hypotheses pertaining to the influences of individual disposition and workplace structure on a city employee's willingness to bend organizational rules.

The article begins by exploring images of rule bending in the literature. The second section outlines hypotheses pertaining to rule bending, while the third section details the study's research design. The fourth section reports the results of statistical modeling, with the fifth section discussing the results in light of the hypotheses posed. The sixth and final section provides concluding remarks.

\section{Rule Bending in the Literature}

Given that rule rigidity is the common characteristic of bureaucratic personality portrayals, it follows that a key characteristic of the un-bureaucratic personality is rule bending, defined as a willingness to depart from rules and procedures. There is substantial evidence that employees at all hierarchical levels bend rules, although it appears to be more the exception than the rule (Blau 1963, Maynard-Moody and Musheno 2003, 92, March 1994, 73). This section reviews images of rule bending in public administration, with an eye towards identifying common elements that may reflect the unbureaucratic personality.

Thompson (1977), who portrayed bureaupathic rule sticklers, also provides an unflattering rule-bending personality: the bureautic (which presumably rhymes with neurotic). This person is immature and insistent on immediate gratification, childhood traits not outgrown in adulthood. Given that this person detests control, organizational life is torturous and all organizational demands are perceived as red tape. Rules and processes remind the bureautic that 
s(he) is not in control and dependent on others. Characterized by low levels of abstraction and a preference for personalized relationships, the bureautic cannot understand the need for rule requirements and interprets them as impugning his or her trustworthiness and dignity. Thus the bureautic does not bother to learn rules or rule purposes and, as a result, constantly violates them (1977: 175).

Blau's study of bureaucracy in the textile division of a state unemployment agency features front-desk receptionists who shortened mandatory minimum timeframes before which jobless clients could return to the agency $(1963,29)$. This rule deviation had the effect of increasing receptionist morale by making them feel like they were doing something positive for downtrodden clients. The first-line supervisors, understanding the value of receptionist morale and figuring that this deviation did not interfere with their own tasks, allowed and even justified the deviation by noting the lack of a simple rule for "due-date" assignment. The department head reacted negatively to the rule deviation because the receptionists' discretionary assignments of due dates flooded the division with clients, resulting in inequitable treatment of clients (in some instances based on race). Her response was to clarify the original procedure and eventually eliminate screener discretion. This scenario led Blau to conclude that perceptions of rule bending will depend on one's place in the hierarchy and how rule bending affects immediate work objectives.

Cohen $(1965,1970)$ replicated Blau's study in a different branch of the same unemployment agency that Blau studied. Cohen observed similar forms of rule deviation, as well as more egregious rule-bending involving racial discrimination. In Cohen’s division, unemployment counselors violated state law by failing to report racially biased employer hiring practices and secretly coding high school job fair attendees by race. With regards to their failure 
to report discriminatory hiring practices, unemployment agents went one step further and instructed employers on how to racially discriminate without getting caught. In this case, the counselors believed their actions to be prosocial: to avoid getting important community employers in trouble, to retain discriminating clients, and to spare the feelings and cabfare of nonwhites who would not be hired.

Bensman's and Rosenberg’s (1963) rule benders are employees who are attempting to compensate for their sense of organizational powerless or for their lack of identification with their employing organization (p. 313). For example, front-line workers will break rules in order to "cut slack" to clients or subordinates with less power than themselves, either as a means to empower themselves or identify with the client. This rule-bending can encompass failure to carefully review client claims for resources or covering up for subordinates who make mistakes. From the perspective of Bensman and Rosenberg, such rule bending costs the organization dearly, but is viewed sympathetically and favorably by society (p. 314).

Maynard-Moody and Musheno’s rule benders are street-level bureaucrats - cops, teachers, and counselors -- who define themselves as agents of the citizen-clients they serve (2003). In this capacity, street-level bureaucrats judge the worthiness or unworthiness of clients in deciding whether to bend rules. Agents bend rules for worthy clients - sometimes at significant professional risks -- for whom following the rules would render an outcome incompatible with the street-level agent's beliefs about how the situation should turn out. By contrast, agents rigidly comply with rules when clients do not merit rule bending or deserve punishment that can be achieved by rigid rule application. The extent to which street-level bureaucrats perceive citizens as worthy or unworthy can depend on the client's seeming sincerity, their responsiveness to requirements, the agent's estimation of the likelihood for 
individual behavioral change, and the client's seeming respect for the agent's authority. In the final analysis, rules are a secondary consideration to the agent's moral assessment of client worthiness in determining how public services will be administered to individual citizens.

These rule-bending portrayals raise several themes potentially relevant to the unbureaucratic personality. With the exception of Thompson's bureautic - who thoughtlessly violates rules because s(he) has not bothered to learn them - the remaining rule benders knowingly violate procedure, thus rule bending is conceptualized as intentional behavior. Thompson lends the notion that rule bending may be purely a function of individual disposition, while Blau and Maynard-Moody and Musheno’s rule bending seeks to overcome procedures perceived as barriers to job performance. The normative view of rule bending is mixed: Blau and Maynard-Moody and Musheno acknowledge that rule bending entails organizational winners and losers, while Thompson, Cohen and Bensman and Rosenberg emphasize the negative organizational and societal costs of the behavior. These themes will be revisited shortly. For now, the next section hypothesizes specific correlates of rule-bending, drawing on rule bending behavior from a range of social science disciplines.

\section{Hypothetical Influences on the Unbureaucratic Personality}

In the tradition of bureaucratic personality scholarship, personality is conceptualized as outwardly observable behavior that is influenced by both personal disposition and environment (Allinson 1986, 43). Accordingly, the unbureaucratic personality is defined as rule bending intentions and attitudes that are expected to be influenced by both individual disposition and organizational structure. This section explores the theoretical foundations of these expectations, beginning with individual disposition. 
Disposition and Rule Bending. Nonconformity, risk propensity, and public service commitment are attributes of individual public employees thought to influence rule bending. Conformity and risk propensity have long been called upon as explanations for rule behavior, although with varying levels of success (Knapp 1964, Knapp 1963, Mulder 1971, Gordon 1970). And while public service commitment has not been addressed in the rule bending literatures, it has been admiringly, anecdotally, and implicitly noted in profiles of public servants who shatter bureaucratic stereotype (Goodsell 2004, 107).

Nonconformity is a logical starting point for examining disobedient behavior. The scholarly definition of nonconformity is the extent to which individual behavior is driven by internal rather than external standards (Kohn 1977, 35). Thus, from the standpoint of a nonconformist, "the system" does not determine whether s(he) follows the rules. To illustrate, a study of enlisted navy men found that those disciplined for violating rules displayed more nonconformist traits than those not subject to disciplinary action (Knapp 1963, 1964). Staw and Boettger note that task revision (which includes rule bending) by definition involves a certain degree of nonconformity to resist social norms and practices (1990: 538). Conversely, Gordon found that study subjects that valued conforming behavior displayed more "bureaucratic orientation," defined in part by the desire for security that rule compliance affords (Gordon 1970). Assembling these strands of evidence, it is expected that public employees with more nonconforming dispositions will exhibit more unbureaucratic personalities $\left(\mathrm{H}_{1}\right)$.

An individual's propensity for risk, which is thought to take seed in early life and germinate in adulthood (March 1994, 41), is another potential explanation for rule behavior. Conceptually, risk aversion has been associated with rule rigidity: Down's conservers - typically middle managers lacking promotion potential - avoided rule deviation to protect their 
organizational positions (1967). Risk aversion also plays into portrayals of "complacent” streetlevel bureaucrats, typically minority or non-college educated workers who engage in an "acquiescent and unimaginative use of agency procedure" to secure their position and occupational status (Stone and Feldbaum 1976). By contrast, the rule-bending entrepreneurial public manager is envisioned as an inherent risk taker, with empirical evidence correlating individual risk-taking propensity with procedural violations (Mulder 1971) and pro-social rule breaking (Morrison 2006). And while it is uncertain that Maynard-Moody and Musheno's citizen agents have more risk-taking dispositions, they clearly took professional risks in bending the rules to provide justice for their clients $(2003,19)$. So did O’Leary’s “Nevada Four”, who risked their jobs by violating standard operating procedures (along with strategies) to protect wetlands from the Bureau of Reclamation’s irrigation practices (2004: 38). For these reasons, it is hypothesized that public employees with greater risk-taking propensities will exhibit more unbureaucratic personalities $\left(\mathrm{H}_{2}\right)$.

In contrast with nonconformity and risk taking, public service commitment is a novel explanation for rule bending behavior. Public service commitment is a dimension of public service motivation, defined as an unmet psychological need that is uniquely or partially fulfilled in public sector work (Perry and Wise 1990; Perry 1996). Commitment to public service may influence rule bending by inspiring employees to go above and beyond the call of duty including bending rules - to further the public interest. While not pertaining to rule bending, the public service motivation literature clearly expects employees with higher PSM to be better performers (Perry and Wise 1990, Naff and Crum 1999), an expectation that has received some support (Naff and Crum 1999, Alonso and Lewis 2001, Frank and Lewis 2004). While the link between high performance and rule-bending is unclear, evidence suggests a relationship between 
commitment and unbureaucratic behavior. For example, Maynard-Moody and Musheno's streetlevel bureaucrats bent rules based on their own personal commitment to clients perceived as worthy (2003). A similar example is found in Hutchinson's study of rule bending among nurses, in which she argues that "A principled level nurse ... questions rules that do not serve human values” (1990: 4). By contrast, Down’s rule-rigid middle managers had no such sense of commitment, either to clients or their agency $(1994,100)$. In the most direct evidence linking a desire to serve and rule bending, private sector employees cited excellent customer service as their reason for bending rules (Morrison 2006). This evidence leads to the expectation that public employees with higher public service commitment will exhibit more unbureaucratic personalities $\left(\mathrm{H}_{3}\right)$.

Organizational Structure. Organizational structure is expected to suppress the unbureaucratic personality by signaling organizational expectations and posing noncompliance consequences. Consider that males confined for misbehavior (in a naval brig, a juvenile detention center, a state security hospital, and a prison reception center) were found more likely to think rules should be strictly followed than nonconfined high school and college-aged males (Gordon 1960). Given that the confined males were societal rule benders functioning in highly controlled environments, the result suggests that organization control significantly influences attitudes towards rule compliance. Three types of structure are expected to affect rule bending: formalization and centralization, which are expected to suppress the unbureaucratic personality, and red tape, conceptualized as active but ineffective structure (Bozeman 2000) and expected to stimulate the unbureaucratic personality.

Formalization is defined as the extent of written rules, regulations and procedures in an organization (Pugh, Hickson and Vinings 1969, 116). Formalization has been associated with 
lower rates of inappropriate rule bending in the private service sector (Kelley, Longfellow and Malehorn 1996), a phenomenon potentially attributable to the veneer of neutral authority and distraction from individual power that formalization provides (Gouldner 1954, 165). Rather than an imperfect human being supplying a mandate, requirements emanate from impersonal, seemingly unbiased written instructions. The foremen in Gouldner's industrial bureaucracy understood this phenomenon well and would not hesitate to blame written rules for directives that underlings resisted $(1954,166)$. Based on this rationale, this study predicts that public employees in workplaces with higher formalization will exhibit less unbureaucratic personalities $\left(\mathrm{H}_{4}\right)$.

While formalization is thought to distract from power disparities, centralization - the upward locus of decision power -- illuminates them. With power inequity front and center, fears of violating organizational norms and incurring noncompliance consequences may lower a public employee's willingness to bend rules. The assertion is supported by studies detecting more rigid and conformist senior managers in highly centralized settings (Ellis and Child 1973) and lower rates of rule-bending among private sector employees with less decision-making autonomy (Morrinson 2006). On a contradictory note, Allinson found centralization to be correlated with less bureaucratic orientation among public and private sector employees, a result he attributed to decentralized organizations recruiting bureaucratic personalities and vice versa $(1984,95)$. It should be noted, however, that Allinson's measure of centralization pertained to the number of core organizational decisions, such as such as the creation of a new department or product pricing, that were made at the highest hierarchical levels. This study, by contrast, borrows Aiken and Haige's conceptualization of centralization as pertaining to workplace decisionmaking (1966, 498), a choice which aligns with other studies finding a link between 
centralization and unbureaucratic tendencies (Ellis and Child 1973, Morrinson 2006).

Accordingly, it is expected that public employees working in more centralized workplaces will exhibit less unbureaucratic personalities $\left(\mathrm{H}_{5}\right)$.

Red tape, defined as active but ineffective organizational rules (Bozeman 2000), is also thought to influence rule bending. Bending rules perceived as red tape may represent a form of task revision, a behavior in which employees alter procedures that they perceive to be faulty (Staw and Boettger 1990), or a value conflict, which leads public servants to violate rules that hinder public goals (Thacher and Rein 2004). These contentions are supported by a study of nurses who bent rules perceived as interfering with their ability to care for patients (Hutchinson 1990), as well as Maynard-Moody and Musheno’s citizen agents, who bent rules that violated their sense of how the situation "ought" to end (2003). This evidence leads to the final expectation, that public employees encountering higher levels of workplace red tape will exhibit more unbureaucratic personalities $\left(\mathrm{H}_{6}\right)$

\section{Research Design}

The data for examining the unbureaucratic personality were collected through a study of the employees of four cities in a Midwestern U.S. state: a small agricultural community (City A); a small city with a light industrial economic base (City B); a mid-size city located near a military base (City C); and an affluent metropolitan city (City D). These cities were included based on their willingness to participate in the study. While the participation of four cities in a single state has implications for the study's external validity, it strengthens internal validity by holding state-

level factors constant. The study entailed ninety in-person interviews with city employees from a range of hierarchical levels and departments, and a mail survey distributed to all employees of each city. The study was executed between June 2005 and December 2006. 
The interview process was designed to generate qualitative data for the larger research project (a study of workplace rules) and inform development of the mail survey instrument. Within each city, interview invitations were sent to a random sample of employees. Interviews were held in conference rooms located away from employee worksites. At the outset of each interview, the researcher explained the study purposes, the confidentiality of results, and the terms of the interview consent form, and provided the employee time to ask questions about the study. Once the interview consent form was signed by both researcher and employee, the employee was asked semi-structured, open-ended questions about their role in the organization, the type of rules they encountered in the workplace, and their impressions of workplace rules.

The mail survey instrument asked questions about workplace characteristics, personal attributes, and attitudes towards rules and rule bending. (The interview protocol is provided in Appendix 1). The survey process began with an alert letter from the city manager's office to employees expressing support for the study and encouraging participation. Within two weeks, an envelope was attached to employee paychecks that contained a personalized cover letter from the researcher inviting survey participation and stressing the confidentiality of results; the mail survey; a stamped return envelope addressed to the researcher's university; and a postcard with a survey identification number that employees were asked to return separately from the mail survey. Thus completed surveys were returned anonymously, while the separate postcards enabled survey responses to be tracked. ${ }^{1}$ This process produced response rates of 61 percent in City A, 83 percent in City B, 43 percent in City C, and 45 percent in City D. The overall response rate was 49 percent ( $\mathrm{n}=645$ ). While it is difficult to discern the factors that account for these differential response rates, Cities A and B have fewer employees while Cities C and D 
have more employees. Consequently, response rates may be a function of the ease of encouraging survey participation.

\section{Qualitative Evidence}

Before delving into statistical analysis, it is worthwhile to discuss city employee perspectives on rule bending gleaned from in-person interviews. Interviews were unstructured and focused on employee perceptions of good versus bad rules (however they defined those terms). While interviews maintained a general focus, employees indirectly revealed their tendencies towards rule compliance or deviation.

Consistent with the study hypotheses, some employees attributed their stance on rules to their own dispositions. To illustrate, a journeyman in a parks and recreation department explained that it was "his nature" to question rules that had been on the books for a while. A utility billing clerk stated that she follows the rules because "that's how I am". A public works secretary noted that she likes rules because they are part her, giving her structure, balance, standards and order. Another secretary in a traffic unit commented that she liked rules because she is an organization "freak" and likes to have things "in order".

Some city employees cited their own conforming dispositions in explaining their attitudes towards rules. One parks and recreation supervisor explained that she was not one to "buck the system” when it comes to rules, indicating her submission to the external system in determining rule compliance. Further up the organizational hierarchy, a public works assistant director noted that he does not think of rules as bad because they are "needed for society." Institutional indoctrination surfaced as a driver of individual conformity, from the administrative program coordinator who remarked that she did not think of rules as good or bad because her family 
prepared her to "respect the mission," or the building code inspector who noted that he was "army-trained" to follow procedure.

Confessions of rule bending were less common, but revealed two rationales consistent with the hypotheses. The first rationale for rule bending was to cut through perceived red tape. For example, a parks and recreation supervisor noted that official procedures for awarding compensation time (which gives future time off in exchange for overtime worked today) were burdensome and useless, leading him to track comp time off-the-record. The supervisor did not regard the centralized regulation as effective and thus regarded the procedure as expendable. Similarly, a street department worker reported sneaking out from under his boss's watchful eye to trim trees that hung over the sidewalk, thus violating the rule to first obtain permission from the property owners:

Property owners are never there and the department head doesn't like to see tree limbs hanging over the sidewalk. The rule makes no sense; the tree limbs are blocking public space.

In this instance, the rule had a goal indiscernible to the street worker, one that clashed with his department head's preferences, thereby making it ineffective and eligible for bending. In another example, a maintenance technician, aggravated by perceived incessant reminders to wear a seatbelt while driving city trucks, would comply for most trips, but:

One day I had driven across the street without my seatbelt on and the head of my work unit was coming out of the building from a meeting. He asked me whether I'd been wearing my seat belt. I just lied and said yes to avoid the stink.... I can see where they are coming from, but sometimes it's petty.

In the maintenance technician's view, the rule became ineffective when it sought to impose "petty" control over him, leading him to ignore the rule and lie to the boss about his compliance. These examples suggest that city employees make judgments about bending rules based on their 
perceptions of rule effectiveness, with ineffective rules regarded as justifiability - albeit clandestinely -- bent.

In alignment with the public service commitment hypothesis, some city employees admitted to bending rules to benefit their cities or the communities they served. Consider the comments of the transportation and maintenance foreman, who notes:

Only streets that are dedicated to the city are supposed to be maintained by the city. But if there's a hole in town, whether it's dedicated or not, I deal with it. I'll just sneak out and fill the hole. I try to make the town look better.

This same employee expressed concern for the effect of poorly maintained sidewalks on wheelchair-bound citizens. The executive secretary in a public works department who worked overtime without the prerequisite permission displays a similar conviction:

I knew major projects were coming up and I had three choices: not do the job, do the job and ask for overtime or comptime, or do the job and ask for nothing. Given the city's budget issues, I chose to stay late on a Friday, which was a holiday, and not ask for anything in return. I am a loyal, dedicated employee concerned for the community and social engineering, I've given my best.

In these examples, employees bent rules to serve broader purposes, even though they had nothing to gain and, in fact, something to lose for their actions: the administrative assistant's boss later chastised her for not clearing her volunteer holiday work with him and the foreman later noted that, "If I get my ass chewed for filling potholes, so be it."

These stories put "flesh on the bones" of the theoretical hypotheses. The next section explores how well the hypotheses hold up to statistical scrutiny.

\section{Models and Measures}


The unbureaucratic personality is modeled as a function of employee disposition and organizational structure. The dispositional variables include nonconformity, risk propensity and public service commitment. Organizational attributes are formalization, centralization, and red tape. The statistical model used is ordered probit regression, which is appropriate for analyzing ordinal data, for which the exact differences between variable levels is unknown (Long 1997, 114).

The unbureaucratic personality is measured as the sum of survey respondents' levels of agreement or disagreement with nine statements (coded from $0=$ strongly disagree to $3=$ strongly agree) that tap attitudes and intentions towards rule bending (table 1). The statements tap motives for bending rules that are both selfish (e.g., I will bend a rule if it makes my job easier) and altruistic (e.g., I will bend a rule if it helps me do a better job for the city) as well as neutral (When I don't understand a rule's purpose, I question it.). The minimum possible scale value is 0 and the maximum possible scale value is 27 . The statements were adapted from studies of bureaucratic orientation by Baker (1972) and Gordon (1970), as well as from patterns of comments made by city employees during the interview process. Cronbach's alpha for the scale is 0.76 .

\section{[Table 1 Here]}

Nonconformity is measured by summing responses to a survey question that asks city employees to rate themselves on a five-point scale between the following opposite characteristics:

Going Along-Arguing

Accepting the System-Questioning the System

Stable-Changing

Accepting Authority-Questioning Authority

Conforming-Rebelling 
Each item is coded from 0 to 4 , thus nonconformity scale values range from 0 to 20 . The scale is adapted from Ellis and Child’s study of managerial conformity (1973). Cronbach's alpha for the scale is 0.83 .

Risk propensity is measured as a survey respondents’ level of agreement or disagreement (0=Strongly Disagree to 3=Strongly Agree) with the statement "I like taking risks at work," adapted from Ellis and Child (1973).

Public service commitment is measured using a scale that sums survey respondents’ levels of agreement or disagreement (from $0=$ strongly disagree to $3=$ strongly agree) with the following statements:

Public service is important to my self-image.

I am proud to be a public servant. I dislike being a public servant (Reversed) I do not identify with being a public servant. (Reversed) I am enthusiastic about public service.

The scale was borrowed from Meyer, Allen and Smith (1993), who devised it to measure emotional commitment to an occupation, but acknowledged that researchers wanting to measure emotional commitment to specific occupations could do so by simply substituting the appropriate descriptor (in this case, “public service”). Cronbach’s alpha for the scale is 0.81 .

Centralization is measured as the sum of survey participants' level of agreement (Strongly Disagree=0 to Strongly Agree=3) with the following statements:

I must check with my supervisor before I do almost anything.

In general, an employee wanting to make their own decisions in my workplace would be quickly discouraged.

Even small matters have to be referred to someone higher up for a final answer.

Only supervisors can decide how things are to be done. 
These statements are adapted from Aiken and Hage (1966). Cronbach's alpha for the scale is 0.73

Aiken and Hage (1966) also provide this study's measure of formalization, reflecting a survey respondent's level of agreement of disagreement with the following statement: Whatever situation arises, my department has written policies and procedures to follow. Responses are coded from 0 (Strongly Disagree) to 3 (Strongly Agree).

Red tape is measured using by survey responses to the following question:

If "red tape" is defined as burdensome administrative policies and procedures that have negative effects on the city's performance, please assess the level of red tape in the City of (Please enter a number in the box between 0 and 10, with 0 indicating no red tape and 10 indicating the highest level of red tape).

This question was adapted from Rainey, Pandey and Bozeman (1995).

The control variables for the model include gender ( $0=$ male, $1=$ female); three occupational statuses measured in two dummy variables, one for supervisors or department heads, one for administrative or policy staff, otherwise front-line workers; length of city employment in years; college education (1=bachelors degree, some graduate school or graduate degree, otherwise $=0$ ); professional association membership; and city of employment, measured in three dummy variables and ordered by increasing number of employees.

Table 3 provides descriptive statistics for the model variables. The unbureaucratic personality variable exhibits a normal distribution with a mean and median roughly equal to 12 , which is slightly less than half the maximum scale value of 27 . The average nonconformity scale value is somewhat lower than the mid-range scale value (8.5), indicating a slight tendency in favor of conformity. The average public service commitment variable indicates high public service commitment among survey respondents. City workplaces appear more decentralized 
than centralized and divided roughly evenly between higher and lower formalization, with a slight tendency towards higher red tape.

[Table 3 Here]

With regards to control variables, female employees are slightly overrepresented in the sample, comprising 28 percent of the sample compared with 25 percent of the city employee population. Survey respondents average ten years on the job, with tenures extending to 38 years. The distribution of respondents by hierarchy mimics a pyramid structure, with descending percentages of front-line workers, supervisors, administrative or policy staff, and department heads. The sample appears well-educated, with over half having college degrees and nearly sixty percent indicating membership in a professional association (which for city employees typically indicates union membership). Six percent of the sample responses come from City A, 14 percent from City B, 21 percent from City C, and 59 percent from City D.

\section{Results}

The ordered probit model results, provided in table 4, indicate that employee disposition influences the unbureaucratic personality in expected and unexpected ways. Nonconformity and risk-taking propensity significantly correlate with the unbureaucratic personality, as hypothesized ( $\mathrm{p}<0.01$ and $\mathrm{p}<0.05$, respectively). However, public service commitment negatively correlates with the unbureaucratic personality, contradicting expectations $(\mathrm{p}<0.10)$.

[Table 4 Here]

The organizational structure hypotheses also receive mixed support. As hypothesized, red tape is positively correlated with the unbureaucratic personality scale $(\mathrm{p}<0.10)$. However, centralization, is correlated with higher levels of the unbureaucratic personality, contradicting 
expectations $(\mathrm{p}<0.01)$. Formalization exhibits a negative correlation to the unbureaucratic personality, as expected, although at borderline statistical significance ( $\mathrm{p}<0.10$ for a one-tailed test). Of the control variables, only gender is a statistically significant influence $(\mathrm{p}<0.01)$, with city employees who are women indicating lower unbureaucratic personality scale values.

Examining fully standardized coefficients of the explanatory variables, nonconformity exerts the largest relative influence on the unbureaucratic personality, followed by centralization with the second largest fully standardized coefficient. McKelvey and Zavoina's $\mathrm{R}^{2}$, which for ordinal outcomes most closely approximates the ordinary least squares (OLS) $\mathrm{R}^{2}$ statistic (Long \& Freese, 2003, 163), is 0.25 for this model. ${ }^{2}$

\section{Discussion}

Beginning with dispositional influences on the unbureaucratic personality, nonconformity appears to increase the unbureaucratic personality, as expected. The result makes sense and is consistent with previous studies $(1963,1964)$. Gordon 1970): nonconformists behave in ways that fit their own internal standards and not the external constraints imposed by the managerial systems in which they reside. Risk propensity also correlates with the unbureaucratic personality,

as expected, suggesting that those individuals inclined to take workplace risks are more willing to bend rules than those more risk averse. This result too is consistent with prior research (Mulder 1971, Morrison 2006) and supports the notion that rule bending is a deliberate, calculated action.

Perhaps the most striking result is the influence of public service commitment, which contradicts expectations with its negative correlation to the unbureaucratic personality. One explanation for the result is that individuals who indicate commitment to public service have 
been indoctrinated to the "ethic" of consistent rule application, which seeks the equitable delivery of public goods and services. While such a conclusion is beyond the evidence presented here, the implication is provocative and merits further examination.

Out of the environmental variables, centralization appears to foster the unbureaucratic personality while formalization appears to suppress it. This contrast may speak to the very different nature of these control mechanisms. As Gouldner observed in his study of industrial bureaucracy, formalization may be a more palatable form of authority than centralization because it emanates from seemingly impersonal rules and procedures, as opposed to the very personal and seemingly more fallible human command that arises in centralized settings. Thus, centralization may trigger rebellious behavior while formalization reduces it.

Red tape appears to trigger the unbureaucratic personality, as expected. The implication of the result depends on whether the red tape perceived by rule benders exists objectively. True red tape that triggers rule-bending tendencies may indicate a healthy response to an organizational pathology. By contrast, the violation of effective rules perceived as red tape even with good intentions -- represents a chink in the armor of organizational control. The manner in which the unbureaucratic personality diagnoses and responds to red tape is an intriguing question for future research.

What do these results imply for government reinvention efforts? First, government reformists who blame risk-averse bureaucrats for organizational lethargy (Cohen and Eimicke 1995) should consider that nonconforming, risk-taking bureaucrats appear more likely to bend organizational rules. Given that the unbureaucratic personality encompasses both selfish and altruistic rule-bending, such behavior may be organizationally beneficial or pathological. Second, government reformists who advocate de-bureaucratizing public agencies should note 
that, while decentralization appears to lower rule-bending, so does formalization. Thus, advice to reduce written organizational rules to increase flexibility and efficiency may unintentionally reduce cooperation with organizational mandates. Third, if public employees have a greater commitment to public service than private employees (an assertion for which there is evidence (see Boyne (2002) for a review), then these results undermine the assumption of privatization that public and private sector employees are essentially fungible. Consequently if rule-bending is the managerial goal (a paradoxical proposition if there ever was one), then private contractors may wish to seek out employees with less public service commitment.

Beyond the confines of government reinvention, how do these results portray the unbureaucratic personality? Much like psychological inkblots tests, the answer depends on the interpreter, particularly with regard to normative judgments about rule-bending among public employees. For those uncomfortable with public employee discretion, the unbureaucratic personality may appear to be a rebel that reacts negatively to authority, disregards rules arbitrarily deemed ineffective, and lacks commitment to the public good. For interpreters unperturbed by public employee discretion, this character may appear the heroic risk taker, cutting red tape with a machete, and resists the constraints of indoctrination to public service. In the absence of a fuller understanding of the motivations of rule bending, it is unclear which portrait (if not both) more faithfully reflects reality.

Three caveats are in order. First, the study sample comprises the employees of four cities of a single Midwestern U.S. state. While the employees participating in the study are hierarchically diverse, the sample is limited by its geographic and local government emphasis. Future studies should expand the types of government sector employees studied, as well as the geographic locations of study. Second, a fuller understanding of unbureaucratic behavior could 
benefit from alternative explanations such as managerial legitimacy, organizational formality, and individual justice motivations. Such explanatory emphases would strengthen understanding of the normative dimensions to rule bending behavior. Third, it may be time to move away from as the term "personality", which this article employs to highlight rule behavior opposite that of the bureaucratic personality. However, given the role of both dispositional and environmental factors in rule-bending, a more appropriate label for future work may very well be the unbureaucratic public servant.

\section{Conclusion}

It is striking how little empirical public administration research has been devoted to unbureaucratic behavior. Perhaps this inattentiveness is due to the inherent paradox of a behavior that is individually admired but collectively feared. Who among us does not like rules to be bent in our favor? Yet bent rules make tiny cracks in organizational systems, which can accumulate to major fissures in hierarchical power structures. Herein lies another potential explanator for the intellectual dormancy of unbureaucratic behavior: the emphasis on a phenomenon that is beyond hierarchical control and inherently difficult to evaluate. Is such behavior largely pathological? Mostly beneficial? A little of both? While this article begins to sketch a portrait of the unbureaucratic personality, definitive judgments about its nature and consequences have yet to be made. Given the inevitability of rule bending behavior and its paradoxical place in the world of public administration, unbureaucratic behavior deserves wider scrutiny. This article takes a step in that direction in the hope that future studies will follow. 


\section{References}

Aiken, Michael, and Jerald Hage. 1966. Organizational Alienation: A Comparative Analysis. In American Sociological Review.

Allinson, Christopher W. 1984. Bureaucratic Personality and Organisation Structure. Brookfield, VT: Gower Publishing Company.

. 1986. The Industrial Bureaucrat. Journal of General Management 11 (3):47-55.

Alonso, Pablo, and Gregory B. Lewis. 2001. Public Service Motivation and Job Performance: Evidence From the Federal Sector. American Review of Public Administration 31 (4):363-380.

Baker, Sally Hillsman, Amitai Etzioni, Richard A. Hansen, and Marvin Sontag. 1973. Tolerance for Bureaucratic Structure. Human Relations 26 (6):755-786.

Blau, Peter M. 1963. The Dynamics of Bureaucracy. Chicago, IL: University of Chicago Press.

Bozeman, Barry. 2000. Bureaucracy and Red Tape. Upper Saddle River: Prentice Hall.

Bozeman, B., and H. G. Rainey. 1998. Organizational Rules and the "Bureaucratic Personality". American Journal of Political Science 42 (1):163-189.

Boyne, George A. 2002. Public and Private Management: What's the Difference? Journal of Management Studies 39 (1):97-122.

Child, John, and Tony Ellis. 1973. Predictors of Variation in Managerial Roles. Human Relations 26 (2):227-250.

Cohen, Harry. 1965. The Demonics of Bureaucracy: Problems of Change in a Government Agency. Ames, IA: The Iowa State University Press.

1970. Bureaucratic Flexibility: Some Comments on Robert Merton's 'Bureaucratic Structure and Personality'. The British Journal of Sociology 21 (4):390-399.

Cohen, Steven, and William Eimicke. 1995. The New Effective Public Manager. San Francisco, CA: Jossey-Bass Publishers.

Downs, Anthony. 1994. Inside Bureaucracy. Prospect Heights, IL: Waveland Press, Inc.

Ellis, Tony, and John Child. 1973. Placing Stereotypes of the Manager Into Perspective. Journal of Management 10:235-255.

Foster, John L. 1990. Bureaucratic Rigidity Revisited. Social Science Quarterly 71 (2):223-249.

Foster, John L., and Judson H. Jones. 1978. Rule Orientation and Bureaucratic Reform. American Journal of Political Science 22 (2):348-363.

Frank, Sue A., and Gregory B. Lewis. 2004. Government Employees: Working Hard or Hardly Working? The American Review of Public Administration 34 (1):36-51.

Goodsell, Charles T. 2004. The Case for Bureaucracy: A Public Administration Polemic. 4th ed. Washington, DC: CQ Press.

Gordon, Leonard V. 1961. Conformity Among the Nonconformists. Psychological Reports 8:383-383. 1970. Measurement of Bureaucratic Orientation. Personnel Psychology 23:1-11.

Gouldner, Alvin W. 1954. Patterns of Industrial Bureaucracy. Glencoe, IL: The Free Press.

Hutchinson, Sally A. 1990. Responsible Subversion: A Study of Rule-Bending Among Nurses. Scholarly Inquiry for Nursing Practice: An International Journal 4 (1):3-17. 
Kelley, Scott W., Timothy Longfellow, and Jack Malehorn. 1996. Organizational Determinants of Service Employees' Exercise of Routine, Creative, and Deviant Discretion. Journal of Retailing 72:135157.

Knapp, Robert R. 1963. Personality Correlates of Delinquincy Rate in a Navy Sample. Journal of Applied Psychology 47 (1):68-71.

- 1964. Value and Personality Differences Between Offenders and Nonoffenders. Journal of Applied Psychology 48 (1):59-62.

Kohn, Melvin L. 1971. Bureaucratic Man: A Portrait and an Interpretation. American Sociological Review 36 (3):461-474.

-1977. Class and Conformity: A Study in Values. Chicago: The University of Chicago Press.

March, James G. 1994. A Primer on Decision Making: How Decisions Happen. New York: The Free Press.

Maynard-Moody, Steven, and Michael Musheno. 2003. Cops, Teachers, Counselors : Stories from the Front Lines of Public Service Ann Arbor: University of Michigan Press.

Merton, Robert K. 1940. Bureaucratic Structure and Personality. Social Forces 18 (4):560-568.

Meyer, John P., Natalie J. Allen, and Catherine A. Smith. 1993. Commitment to Organizations and Occupations: Extension and Test of a Three-Component Specialization. Journal of Applied Psychology 78 (4):539-551.

Morrison, Elizabeth W. 2006. Doing the Job Well: An Investigation of Pro-Social Rule Breaking. Journal of Management 32 (1):5-28.

Mulder, Frans. 1971. Characteristics of Violators of Formal Company Rules. Journal of Applied Psychology 55 (3):500-502.

Naff, Katherine C., and John Crum. 1999. Working for America: Does Public Service Motivation Make a Difference? Review of Public Personnel Administration 19 (4):5-16.

O’Leary, Rosemary. 2004. The Ethics of Dissent: Managing Guerilla Government. Washington, DC: CQ Press.

Osborne, David, and Ted Gaebler. 1992. Reinventing Government: How the Entrepreneurial Spirit is Transforming the Public Sector From Schoolhouse to Statehouse, City Hall to the Pentagon. Reading, MA: Addison-Wesley Publishing Company.

Rainey, Hal G., Sanjay Pandey, and Barry Bozeman. 1995. Research Note: Public and Private Managers' Perceptions of Red Tape. Public Administration Review 55 (6):567-574.

Perry, James L. 1996. Measuring Public Service Motivation: An Assessment of Construct Reliability and Validity. Journal of Public Administration Research and Theory 6 (1):5-22.

Perry, James L. , and Lois Recascino Wise. 1990. The Motivational Bases of Public Service. Public Administration Review 50:367-373.

Pugh, D. S., D. J. Hickson, and C. R. Hinings. 1969. An Empirical Taxonomy of Structures of Work Organizations. Administrative Science Quarterly 14 (1):115-126.

Shultz, Kenneth S., and David J. Whitney. 2005. Measurement Theory in Action: Case Studies and Exercises. Thousand Oaks, CA: Sage Publications, Inc.

Staw, Barry M., and Richard D. Boettger. 1990. Task Revision: A Neglected Form of Work Performance. The Academy of Management Journal 33 (3):534-559. 
Stone, Clarence N., and G. Feldbaum. 1976. Blame, Pessimism and Complacency: Attitudes and Problem Perceptions Among Selected Street Level Administrators in Two Suburban Counties.

Administration and Society 8 (1):79-101.

Thompson, Victor A. 1977. Modern Organization. 2nd. ed. University, Alabama: The University Alabama Press. 
Table 1. Unbureaucratic Personality Survey Question Items

\begin{tabular}{|l|c|}
\hline Scale Item & Source \\
\hline Even if I dislike a rule, I usually obey it. & Baker 1972 \\
\hline $\begin{array}{l}\text { Often, the only thing wrong with breaking rules is getting } \\
\text { caught. }\end{array}$ & Baker 1972 \\
\hline Following the rules is a matter of personal principal. & Gordon 1970 \\
\hline $\begin{array}{l}\text { If employees just followed all of the city's rules, we would be a } \\
\text { more effective organization. }\end{array}$ & Gordon 1970 \\
\hline $\begin{array}{l}\text { Employees are better off when the city provides a complete set } \\
\text { of rules to be followed. }\end{array}$ & Gordon 1970 \\
\hline $\begin{array}{l}\text { I will bend a rule if it helps to make } \\
\text { better community. }\end{array}$ & City employee interviews \\
\hline When I don't understand a rule's purpose, I question it. & City employee interviews \\
\hline I will bend a rule if it helps me do a better job for the city. & City employee interviews \\
\hline $\begin{array}{l}\text { I could be more effective in my job if there were fewer policies } \\
\text { and procedures. }\end{array}$ & City employee interviews \\
\hline If I think a rule is pointless, I will find a way around it. & Baker 1972 \\
\hline I figure that rules are there for a purpose. & Gordon 1970 \\
\hline I will bend a rule if it makes my job easier. & City employee interviews \\
\hline
\end{tabular}


Table 2. Descriptive Statistics for Model Variables

\begin{tabular}{|l|c|c|c|c|c|c|}
\hline & Mean & Median & Std Dev & Min & Max & Skewness \\
\hline $\begin{array}{l}\text { The Unbureaucratic } \\
\text { Personality Scale }\end{array}$ & 11.95 & 12 & 3.90 & 2 & 25 & 0.21 \\
\hline Nonconformity & 6.64 & 6 & 3.63 & 0 & 17 & 0.13 \\
\hline Risk Propensity & 1.46 & 1 & 0.87 & 0 & 3 & -0.04 \\
\hline $\begin{array}{l}\text { Public Service } \\
\text { Commitment }\end{array}$ & 10.92 & 11 & 3.04 & 1 & 15 & -0.62 \\
\hline Centralization & 4.18 & 4 & 2.68 & 0 & 12 & 0.40 \\
\hline Formalization & 1.54 & 2 & 0.81 & 0 & 3 & -0.15 \\
\hline Red Tape & 6.03 & 6 & 2.47 & 0 & 10 & -0.31 \\
\hline Female Employees & 0.28 & 0 & 0.45 & 0 & 1 & 0.97 \\
\hline $\begin{array}{l}\text { Length of City } \\
\text { Employment }\end{array}$ & 10.32 & 8 & 8.32 & 1 & 38 & 0.76 \\
\hline Department Heads & 0.06 & 0 & 0.24 & 0 & 1 & 3.58 \\
\hline Supervisors & 0.25 & 0 & 0.43 & 0 & 1 & 1.17 \\
\hline $\begin{array}{l}\text { Administrative/Policy } \\
\text { Staff }\end{array}$ & 0.09 & 0 & 0.28 & 0 & 1 & 6.46 \\
\hline Front-Line Workers & 0.48 & 0 & 0.50 & 0 & 1 & 0.10 \\
\hline $\begin{array}{l}\text { Professional } \\
\text { Association } \\
\text { Membership }\end{array}$ & 0.58 & 1 & 0.49 & 0 & 1 & -0.32 \\
\hline College Education & 0.56 & 1 & 0.50 & 0 & 1 & -0.24 \\
\hline City A & 0.06 & 0 & 0.23 & 0 & 1 & 3.88 \\
\hline City B & 0.14 & 0 & 0.35 & 0 & 1 & 2.08 \\
\hline City C & 0.21 & 0 & 0.41 & 0 & 1 & 1.42 \\
\hline City D & 0.59 & 1 & 0.49 & 0 & 1 & -0.38 \\
\hline
\end{tabular}


Table 3. Ordered Probit Model of the Unbureaucratic Personality

\begin{tabular}{|c|c|c|c|c|c|}
\hline & Beta & Std. Beta & $\mathrm{z}$ & $\mathrm{p}(\mathrm{Z})$ & $B(x y)$ \\
\hline Nonconformity & 0.06 & 0.01 & 5.99 & $* * *$ & 0.30 \\
\hline Risk Propensity & 0.16 & 0.06 & 2.81 & 0.01 & 0.12 \\
\hline Public Service Commitment & -0.03 & 0.02 & -1.74 & 0.08 & -0.08 \\
\hline Centralization & 0.06 & 0.02 & 3.41 & $* * *$ & 0.15 \\
\hline Formalization & -0.09 & 0.06 & -1.62 & 0.11 & -0.07 \\
\hline Red Tape & 0.04 & 0.02 & 1.84 & 0.07 & 0.08 \\
\hline Gender & -0.43 & 0.11 & -3.81 & $* * *$ & -0.16 \\
\hline Length of City Employment & 0.00 & 0.01 & -0.85 & 0.39 & -0.03 \\
\hline Department Head Status & -0.14 & 0.19 & -0.75 & 0.45 & -0.03 \\
\hline Supervisor Status & -0.01 & 0.12 & -0.09 & 0.93 & 0.00 \\
\hline Frontline Worker & -0.13 & 0.14 & -0.91 & 0.37 & -0.04 \\
\hline Administrative or Policy Staff Status & -0.10 & 0.12 & -0.89 & 0.37 & -0.04 \\
\hline College Education & 0.05 & 0.09 & 0.59 & 0.55 & 0.02 \\
\hline Professional Association Membership & -0.09 & 0.09 & -0.94 & 0.35 & -0.04 \\
\hline City B & -0.15 & 0.22 & -0.70 & 0.49 & -0.04 \\
\hline City C & -0.15 & 0.19 & -0.78 & 0.44 & -0.05 \\
\hline City D & -0.04 & 0.17 & -0.23 & 0.82 & -0.02 \\
\hline
\end{tabular}

Notes: McKelvey and Zavoina's $\mathrm{R}^{2}=0.26 ; \mathrm{n}=517$; White's robust standard errors used to counteract heteroskedasticity; ${ }^{* * *}=\mathrm{p}<0.01$; probabilities reported for a two-tailed test; $\mathrm{B}(\mathrm{xy})$ represents fully standardized coefficients 


\section{Appendix}

\section{$\underline{\text { Interview Protocol }}$}

Introduction. Describe study purpose, explain that participation is voluntary, see if they have questions before beginning, explain interview consent form, sign and have them sign interview consent form.

Ask about their role and responsibilities within the organization.

First, I would like to ask you about the rules that you encounter in your job. The rules you think of can be regulations, ordinances, or policies that you have to comply with or enforce.

Can you think of a rule (or rules) that you encounter in your job that, in your opinion, is (are) good? What is the rule and what makes it good?

Can you think of a rule (or rules) that you encounter in your job that, in your opinion, is (are) bad? What is the rule and what makes it bad? 


\section{End Notes}

1. The study was conducted in partnership with city managers, who participated in order to generate employee feedback on a range of workplace issues, e.g., performance evaluation processes, career banding systems, and potential policy changes. Paycheck distribution was selected in comparison with distribution to home addresses (which was deemed a violation of employee privacy) and departmental distribution (which raised concerns that employees might be unintentionally or intentionally discouraged to participate if seen taking or declining to take a survey package). Paycheck distribution also offered the advantage of anonymity to superiors: since completed surveys were mailed directly to the principle investigator, supervisors and managers had no way of knowing who did or did not participate. The results of survey and interview data analysis suggest that employees viewed study participation as a mechanism for expressing their voice in a way that they could not do otherwise. For example, critical written comments far outnumbered positive comments, with several employees attaching a page of typed comments to their surveys.

2. Ordered probit assumes "parallel regression," meaning that each explanatory variable has the same effect on the odds of different values of the dependent variable (Long, 1997, 140; Long \& Freese, 2003, 168). 7. As Long and Freese note, this is a frequently violated assumption of ordered probit (p. 168). In response to this model's violations of the parallel regression assumption, the results were replicated using ordinary least squares (OLS) modeling with robust standard errors. The results are identical in terms of the significance and direction of influence of the model variables. A normal probability plot of OLS residuals indicates normality and variance inflation factor (VIF) scores suggest that multicollinearity is not an issue. 